Published as Marginson, Simon (2017). The world-class multiversity: Global commonalities and national characteristics. Frontiers of Education in China, 12 (2), pp. 233-260. DOI $10.1007 / \mathrm{s} 11516-017-0018-1$

\title{
The World-Class Multiversity: Global commonalities and national characteristics
}

Simon Marginson

UCL Institute of Education

University College London, UK

\section{Contact details}

20 Bedford Way

London, WC1H 0AL

United Kingdom

s.marginson@ucl.ac.uk

$+44(0) 7876323949$

Bio

Simon Marginson is Professor of International Higher Education at UCL Institute of Education, University College London in the UK, and Director of the ESRC/HEFCE Centre for Global Higher Education. He is also Editor-in-Chief of Higher Education. 


\title{
The World-Class Multiversity: Global commonalities and national characteristics
}

\begin{abstract}
World-Class Universities (WCUs) are nationally embedded comprehensive higher education institutions (HEIs) that are closely engaged in the global knowledge system. The article reviews the conditions of possibility and evolution of WCUs. Three interpretations are used to explain worldwide higher education: neoliberal theory, institutional theory, and critical political economy, which gives greater recognition than the other theories to the role of the state and variations between states. World higher education is evolving under conditions of globalisation, organisational modernisation (the New Public Management), and in some countries, marketisation. These larger conditions have become manifest in higher education in three widespread tendencies: massification, the WCU movement, and organisational expansion. The last includes the strengthening of the role of the large multi-disciplinary multi-purposes HEIs ('multiversities'), in the form of both research-intensive WCUs with significant global presence, and other HEIs. The role of binary sectors and specialist HEIs has declined. Elite WCUs gain status and strategic advantage through both quantity and quality: through growth and the expansion of scope, and through selectivity and research concentration. The balance between quantity and quality is now resolved at larger average size and broader scope than before. The final section of the article reviews WCUs in China and considers whether they might constitute a distinctive model of university.
\end{abstract}

\section{Keywords}

Comparative Education, Globalisation, World-Class University, University ranking, Research, New Public Management, Massification, China, Institutional theory 


\section{Introduction}

World-Class Universities (WCUs) can be understood as comprehensive nationally embedded universities closely engaged in the global knowledge system. They are more globalised versions of the large university conglomerate, the multi-purpose, multi-disciplinary research and teaching institution that Clark Kerr (1963/2001) described as the 'multiversity'. This article explores the dynamics of World-Class Multiversities, multi-disciplinary universities with sufficient scholarly mass to be recognised in measures of global research performance (e.g. Leiden University, 2017) — which for ease of use will continue to be termed 'WCUs'. It considers the conditions of development of WCUs, in the larger context of national and global systems in higher education, and the main systemic and institutional trajectories associated with this emblematic institutional form. Due regard is given to the scope for, and the presence of, national differences. However, given the wide-ranging character of the article, which covers a rich and complex terrain in a short space, many of the issues discussed here, including national variations, could be usefully explored in more detail.

The term 'global' refers not to the world and everything in it, but to phenomena, systems and relations that are planetary in scale, such as world ecology, or knowledge in mathematics (Marginson, 2010). The WCU is both a national and local strategy, in global context and sensitive to global referents and objectives. All three dimensions of action are in play: global, national and local (Marginson \& Rhoades, 2002). This 'glonacal' perspective is different to the simpler analytical picture called up by global university ranking, a global/local world system of networked higher education institutions (HEIs), in which WCUs are equivalent and interchangeable regardless of their national setting. The global space is a complex relational outcome of global systems, national systems and individual WCU agency (Marginson, 2006).

The article begins by discussing methods of comparison, noting that there are many national and cross-national viewpoints from which to investigate world higher education. It notes three bodies of theory used in such investigations: the neoliberal, the institutional, and the political economy perspectives. In the political economy perspective, the national state is centrally important, along with global systems and effects, in shaping higher education. The article then reviews historical tendencies in higher education and WCUs. First it considers the broader environment, including globalisation, organisational modernisation (the New Public Management) and marketisation. Second, it considers manifestations in the higher education sector, including massification, the WCU movement, and organisational expansion. This last section, which focuses on national system shape and institutional configurations - noting the growing reliance on the large comprehensive or multipurpose multiversity form of HEImight be the original contribution of the article. The concluding section reviews the evolution of WCUs in China and considers whether they might constitute a distinctive model of WCU.

\section{Methods of Understanding WCUs}

\section{National and Cross-National Viewpoints}

From what viewpoint do we understand worldwide higher education, which is both common and diverse across countries? Here the philosophical problem is (a) the relation between general and particular; and (b) which standpoint determines particular and general?

In international and comparative studies there is a natural tension between generalising theories and arguments, and the contextual understanding of cases (Valimaa \& Nokkala, 2014 , p. 425). We need common categories and concepts to map the field and compare nations and institutions with others. We need sameness as the basis for making comparisons so the chosen areas of difference stand out. However, as in all theorising, there is a danger 
that the tools used to render the field of practice visible to observation and analysis will obscure the scope for difference, hiding from view that which is contextually distinctive in particular cases (the same problem is apparent in global research rankings that occlude knowledge not published in English). Worse, the generic tools used by comparative scholars of higher education often simply reflect the norms of the home country of the scholar, obscuring all features of other systems that are unfamiliar in relation to home country norms, or rendering these as deficits. This can be called 'single country myopia' (Valimaa \& Nokkala, 2014, p. 425).

In some methodology, single country myopia is taken further. Shajahan and Kezar (2013) critique 'methodological nationalism' in higher education studies, the belief 'that the nation/state/society is the natural social and political form of the modern world' (Wimmer and Schiller, 2002, p. 301). Methodological nationalism has two costs for explanation. First, it blocks from view any feature of the higher education landscape not part of the mastersystem. Second, it is especially likely to underestimate phenomena that cross borders or pertain to global systems, thereby rendering as marginal to the analysis of the master system such influential phenomena as the world system of codified knowledge in research.

Once the single country vision has been dethroned the potential for multiple perspectives become apparent. There is more than one way to understand global commonalities and systems in higher education and science - in fact there are as many ways to understand all global phenomena as there are national systems and HEIs and persons. For example, as Yang Rui (2014) notes, internationalisation is relatively unproblematic in English-speaking HEIs that work with the dominant English-language templates without the disruption of having to change themselves. However, incorporating an international element into higher education is more double-edged in China, where WCU internationalisation strategies are partly in tension with national identity and inherited practices. Internationalisation of higher education looks different in China from how it looks for practitioners in Toronto, Boston or London.

While universities worldwide are promoting internationalisation, achieving a common definition has not proved simple... Definitions of internationalisation embody diverse emphases and approaches. The most cited [notion] ... defines internationalisation as the process of integrating an international, intercultural, or global dimension into the purpose, functions, or delivery of higher education. It has served the field extremely well, especially in its analysis of activities at institutional level. However, this definition is only based on and thus suitable for Western experience. To non-Western societies, modern universities are an imported concept. They originated from Europe, spreading worldwide from the mid- $19^{\text {th }}$ century to the present time mainly due to colonialism. Even the countries that escaped colonial domination adopted Western models as well. The European-North American university model has never been tolerant toward other alternatives, leading to the inefficacy of universities in nonWestern societies, on whom a so-called 'international' perspective has been imposed from the outset (Yang, 2014, pp. 152-153).

All national viewpoints constitute partial truths yet world higher education is larger than any. This suggests the possibility of combining viewpoints while remaining sensitive to the insights of each - for example, by developing generic conclusions entered by more than one viewpoint. Scholars can displace single country myopia by studying each other's countries and comparing results, or applying each other's templates to their own systems. The methodology of comparative and international studies in higher education offers further options (e.g. Goedegebuure and van Vught, 1994; Goedegebuure, et al., 2014). Scholars from different traditions have much to gain by working together and listening to each other. 


\section{Three Kinds of Theory}

Once viewpoint is resolved - national? which national? cross-national? - there is the question of theoretical interpretation. Three perspectives are used in understanding worldwide higher education: neoliberal theory, institutional theory, and critical political economy (Carnoy, et al., 2013; Chirikov, Watanabe \& Postiglione, forthcoming).

Neoliberal theory understands the worldwide sector as a competition between HEIs in the global higher education market. This imaginary is familiar. It is continually reproduced in policy and popular culture and consistent with global league tables of the Times Higher Education (2017) and Quacquarelli Symonds (2017) type. Note that most global rankings embody the norms and practices of the leading Anglo-American research universities. One of the few exceptions is U-Multirank (2017), which provides comparative data without AngloAmerican normalisation and competitive league table ordering (Marginson, 2014).

The second perspective is that of institutional theory. This again understands HEIs as working to a universal script, with global influences that are uniform and predominantly topdown in character, but the organisational model is not the business firm as in the neoliberal perspective. It is common to all sectors. Drori, Meyer and Hwang (2006) note a convergence in the forms of business, public administration and non-government organisation:

Organisations tend to reflect models in their environments. Such models evolve over time. Organisations often tend towards homogeneity within particular environments and time periods... The environments that support and impact organisations are often organised at very large-scale levels, and increasingly at the world level. National and increasingly global movements provide a context for organising... Preferred models of social organisation arise out of the increasing awareness of an expanding world society. They centrally stress the continued expansion and penetration of formal organisation throughout the world (Drori, Meyer \& Hwang, 2006, pp. vi-vii).

Schofer and Mayer (2005, p. 900) argue that across the world a new model of society is being institutionalised in education, 'reflected in trends towards increasing democratisation, human rights, scientisation, and developmental planning'. In institutional theory, the design of national systems and institutions in higher education, including similar looking WCUs, proceeds on the basis of cross-border imitation of master practices. National policies fall into line with this apparently irresistible global tendency, though one that seems to be top-down and abstract with little regard for human agency. As in neoliberal theory, the master practices embody liberal American values in an echo of Fukuyama's (1989) end of history thesis. This is not methodological nationalism, in that the global dimension is seen as formative, but both neoliberal and institutional theory embody a single country myopia with imperial reach. The possibility of bottom-up variation that articulates and modifies global patterns-let alone the possibility of a non-American model of WCU, for example in East Asia-is not considered.

The third perspective can be called critical political economy. This includes scholars such as Martin Carnoy (1984/2014), Sheila Slaughter and Gary Rhoades (2004), Susan Robertson (e.g. Robertson, et al., 2016), Rajani Naidoo (2004) and Imanol Ordorika (2003). From the perspective of critical political economy, each of neo-liberal theory and institutional theory have insights into worldwide higher education, but both downplay the role of the national state (Carnoy, et al., 2013, pp. 2-3), and are weak at the level of the national embeddedness of systems and institutions, which shapes differing approaches to higher education across the world, including the distinctive Post-Confucian approach in East Asia 
(Marginson, 2013). Critical political economy brings the state back in (Evans, Rueschemeyer \& Skocpol, 1985) and allows national variations to be better understood.

In the critical political economy approach states are understood as 'competition states' (Cerny, 1997) for whom universities provide resources for economic innovation and global competitiveness and a national framework of social opportunity. WCUs are seen as selfdetermining actors with agency that respond, imitate and initiate within the global settingrather than being blindly moved around by global forces or scripted by master practiceswhile at the same time being positioned in, and shaped by, nation-state agendas and funding. In most countries, the state is at least as significant a driver of WCU development as the institution. Research capability is closely affected by the level of state funding for R\&D in higher education. In contrast to neo-liberal theory, some scholars working in critical political economy also note that higher education does not function in the manner of orthodox capitalism. Higher education produces positional goods, which at the top end of value are limited in total number and subject to price inelasticity of demand, this is not a demand/supply market; and basic research, which is a classic public good subject to market failure. States never fully deregulate higher education because of its part public good character and political importance (Marginson, 2016d, pp. 151-179).

In this perspective both the national and local institutional contexts articulate global relations and flows in higher education, including cross-border flows of knowledge and talent and the networking activities of WCUs. The articulation varies by time, nation, institution, and by domain of activity; and is also affected by whether state coordination is achieved using legal, financial or episodic political interventions (Carnoy, Froumin, Leshukov \& Marginson, forthcoming). However, the point is that national context always matters. Higher education cannot be meaningfully separated from the state any more than it can be separated from society. No one in universities anywhere likes forceful state intervention. At the same time, in most countries it is taken for granted that higher education-including regulated private education in many countries - is a matter of public interest, and 'public' means politics and the state (Dewey, 1927). This becomes more obvious when scrutiny moves from US political culture, with its strong strand of anti-statism, to countries with a tradition of comprehensive states rather than limited liberal states, as in the Nordic world and East Asia.

Why do neo-liberal theory and institutional theory both downplay the role of nation and state? The neoliberal argument emerged at the high point of 1990s deregulations in trade and finance when many observers, not just neoliberal economists, thought that national forms were decisively losing ground, amid the roll-out of world markets and the development of worldwide communications via the Internet. The assumption the nation-state had been decisively undermined by globalisation - rather than the lesser claim that the nation-state had been relativised by globalisation, with world systems increasingly influential—was undermined by the subsequent course of world events, especially after the terrorist attacks on the US in 2001 and the US response. Amid the politics of security, terror, migration, free trade, war in the Middle East and Africa and tensions on the borders of China and Russia, 1990s globalism is looking increasingly frayed.

In addition, notions that the nation plays a secondary role in higher education, and the most important factors are the local and the global, have been unduly conditioned by the American case. As noted the US state is partly concealed by anti-statist ideology - the US presents itself as the most limited of the limited liberal states in the John Locke/Adam Smith tradition, so that some even see taxation as a form of theft (Marginson, 2016c, pp. 126142) — and by social arrangements. The US is unusual in its configuration of WCUs, civil society and the state. Civil organisations, such as accreditation agencies, often carry out roles performed in other nations' state agencies. Conversely, elsewhere most WCUs are seen as autonomous state institutions, but in the US become independent civil institutions positioned 
at a long remove from the limited liberal state. The US tradition of separated but interlocking powers enables universities to appear as independent institutions without becoming socially autarkic or wholly outside education policy. Yet even US WCUs are closely affected by law and budget decisions, are subject in the public sector to state policy on admissions, are resources and reference points for the state, and are thoroughly embedded in the broader American political culture based on shared beliefs (Mettler, 2014). The fact that the leading Ivy League and public sector WCUs operate across the world with a quasi-imperial reach does not mean they are stateless multinational corporations. They embody a common patriotism abroad, where they synchronise with US embassies. They conduct research crucial to the military. In short, US research multiversities are not the disembedded free-wheeling local/global actors imagined in neoliberal theory and in their own public rhetoric.

\section{National-Cultural Variation}

Some scholars in the political economy perspective emphasise that states and nations are nested in and articulated through history and culture, underlining the potential for national variations in the political economy of higher education itself (Carnoy, et al., 2013; Marginson, 2016d, p. 119ff.). The case studies of universities in China by Hayhoe, Li, Lin and Zha (2011) also draw out the potential potency of cultural factors. The present dynamism of East Asian higher education and science again suggests that cultural factors are at work.

In East Asian WCUs, two of the motors of development - comprehensive and focused states in the Chinese civilizational tradition, and Confucian educational cultivation in the home-diverge from the states and families typical of higher education in North America and Europe (Marginson, 2013). The potential of cultural factors suggests that not only can the forms and practices of leading research-intensive universities, WCUs, vary from country to country; it also may be possible to establish in influential model of WCU that differs from the Anglo-American norm embodied in global rankings. This does not mean that national variation is inevitable, and there is no question that higher education is at least partly globally convergent (King, Marginson and Naidoo, 2011). However, when differing political cultures, state traditions and educational cultures intersect with the common worldwide science system in research and the hitherto dominant template of WCUs, there is potential for hybrid models.

\section{The Worldwide Environment in Higher Education}

Higher education systems and WCUs share a common worldwide environment in which all are touched by globalisation, organisational modernisation and marketisation, though in varying ways. As institutional theory suggests, organisational modernisation is the most ubiquitous of these tendencies, but the forms of modernisation are not identical everywhere.

\section{Globalisation}

All WCUs are continually affected by globalisation, which is understood here as global convergence and integration (Marginson, 2010). All are touched by cross-border flows of knowledge, ideas, systems, people and capital; by global visioning, comparison and ranking; and by evolving global competition and cooperation. The extent to which they are open to and changed by globalisation varies. Global effects do not play out the same in every WCU and nor does every WCU have an identical capacity to reciprocally affect global relations. Like beams of white light, global effects pass through the prism of nation-state and locality. Because the prisms differ, the resulting beams of coloured light also vary. 
The effects of globalisation vary not only in terms of national characteristics but by the domain of higher education under consideration. The most globalised aspects relate to research knowledge, networking, and information flows, including global referencing and ranking. These are global systems, grounded in relationships which cannot be wholly contained within a single national system or blocked at the border. States and universities must simply position themselves to advantage within global systems. However, people mobility is more open to national regulation, through migration regimes and though national and institutional protocols affecting the appointment of foreign staff. Patterns of cross-border imitation in organisational matters also play out differently from country to country.

\section{Organisational Modernisation}

Organisational modernisation, otherwise known as the New Public Management, is the rollout of institutional forms such as executive leadership, performance management, quality assurance, regulated competition, output modelling, efficiency and budget controls, transparency, accountability and protocols ensuring responsiveness (or quasi-responsiveness) to users. As institutional theory states, organisational modernisation is common not just to HEIs but all complex organisations. In a convergent world, with every complex organisation visible to every other, its forms are increasingly similar. Organisational innovations spread through cross-border imitations that can move very rapidly. This kind of ubiquitous cultural movement has a long history. Early examples were the radiation of agriculture (Cuncliffe, 2015), and the passage of world religions (Frankopan, 2015). Later, when modern nations emerged in the late eighteenth century and onwards, competition states led organisational reform, which began first in the military and industrial spheres (Bayly, 2004). In the Internet era, communicative globalisation accelerates the transfer of models and exemplary practices. States often play the driving role in organisational reform in higher education, though some HEIs move ahead. Organisational modernisation in higher education is also quickened by massification and larger more multiple HEIs (see below). Corporate forms are used to manage coordination, resource efficiency and entrepreneurial decentralisation.

This does not mean that all HEIs everywhere look and feel the same and function by identical laws. Rather, common design features such as executive leadership and quality assurance are articulated through the range of national and local sites and inflected by diverse histories and cultures. There is continuing variety in organisation, coupled with a worldwide similarity larger than before. The continuing differences are often important. The extent to which HEIs have adopted business forms varies by country and many countries also exhibit variation within the sector. For example, in East and Southeast Asia some universities rectors or presidents are elected by and responsive to faculty (e.g. in certain WCUs in Japan), while others are variously appointed by the nation-state (e.g. China, public universities in Malaysia) or the university's governing body (e.g. Singapore). In English-speaking WCUs the power of traditional faculty governance seems to peak in established top flight WCUs, such as Oxford or UC Berkeley, which at times almost seem to manage themselves. The scope for executive leadership seems greater in WCUs where capacity is in the process of being built.

Forms of doctoral training and academic careers vary significantly. Musselin (2005) traces diversity among Germany, France and the UK in the procedures for appointing and promoting academic faculty, their pay scales, and workload regulation. The extent of internationalisation also varies. In some countries (e.g. Switzerland, US) it is much easier for foreigners to access career academic posts than in others (e.g. Spain, Malaysia).

\section{Marketisation}


Since the 1980s, neoliberal marketisation has influenced reforms in public administration, but its incidence in higher education is less universal than either organisational modernisation or WCUs. Marketisation includes the roll-out of quasi-market systems, extending beyond competition to private financing and user charges, the fostering of campus entrepreneurship, and growth in the role of the private sector. It also includes overtly commercial activity entailing production for profit, for example in fee-paying education of international students in the UK, Australia and New Zealand, certain forms of vocational education, for example in the for-profit sector in the US (Mettler, 2014), and commercial research and consultancy.

Although the emphasis on WCUs in many countries might seem to enhance the potential for high value private goods, not all systems have responded this way. Marketisation is highly uneven. In the US sector, long understood as a market, sharp differences in the value of private benefits in a stratified sector provide a clear basis for family investment strategies (Marginson, 2016d). UK and Australian HEIs have been transformed by neoliberal reforms since 1988. The UK moved from a publicly financed system with no tuition fees to a studentcentred market with a near universal $£ 9000$ charge, albeit softened as in Australia by income contingent loans (Dearden, 2017). Tuition fees and private sector growth have changed the sector in Russia and some other post-Soviet countries (Smolentseva, 2017). Private HEIs in India, the Philippines and Brazil have the main role in massification. However, market forms have a lesser degree of impact in some Western Europe and Latin American countries, though increased competition in research grant allocations in widespread. Tuition is free or low cost in Germany, the Nordic countries (Valimaa, 2011) and France, and in public higher education in Turkey and Mexico. Neoliberal reforms have been reversed in Chile where tuition is now free for poorer families (Guzman-Valenzuela, 2016). Privatisation has been partly reversed in Poland (Kwiek, 2016).

East Asia has long been characterised by stratified systems with differences in private benefit, and tuition fees in most countries, yet in East Asia, the transformative impact of marketisation evident in the reformed higher education systems of the United Kingdom and Australia (Marginson and Considine, 2000; Marginson, 2017) has been partly contained by the state. Though in South Korea and Japan households pay over half of the cost of higher education (OECD, 2015, p. 248), government closely supervises the conduct and quality of private HEIs. In China student fees were introduced in 1997, the year that labour allocation of graduates was abolished, both moves signifying a partial shift to a private good approach to higher education (Cheng and Yang, 2015, pp. 134-136), yet the system remains closely focused on national objectives. Among poor families in Post-Confucian East Asia the deterrent effect of fees is modified by universal commitment to education, though feecharging in China has probably had regressive effects on the distribution of opportunities. The outcome is not yet clear. The rapid growth of enrolments has masked other effects.

\section{Manifestations in Higher Education}

These environmental tendencies are manifest in higher education in three ways: the near universal growth of participation ('massification'), the WCU movement, and changes in the configuration of national systems and HEIs, summarised here as 'organisational expansion'.

\section{Massification}

'Mass' higher education, defined by Martin Trow (1973) as national systems enrolling more than 15 per cent of the school leaver age cohort, emerged in all industrialised countries prior to the Internet in 1990. Since the mid 1990s the tendency to massification has spread to all middle-income countries and some poorer countries, and in most countries the rate of growth 
of participation has accelerated. In some systems, for example South Korea, participation is now reaches almost the whole age group. Though the radiation of high participation high education across the world looks like the isomorphistic patterns described by institutional theory, the essential driver is not the abstract global forces of a 'world polity' (Schofer \& Meyer, 2005, p. 904), or even policy imitation by states - which though they sanction the expansion of access, never seem to reverse it — but family demand for social opportunity. The growth of enrolment is more universal and uniform, in the manner of, say, the Neolithic revolution, than is the case with politically-driven tendencies (Marginson, 2016a; 2016b). At the same time, the systemic and institutional structures joined to family demand, in nationally-embedded massified systems, demonstrate substantial variations across the world.

UNESCO Institute of Statistics data show that forty years ago no country enrolled more than 50 per cent of the school leaver age cohort in 'tertiary education', meaning programmes of two-years full-time equivalent or more. By 2014, 56 national systems, a third of the total, had reached that level of participation in tertiary education. Another 56 countries enrolled between 15 and 50 per cent of the age cohort (UNESCO, 2017). Given that the majority of 'tertiary' students are at degree level, and taking completion rates into account, these trends suggest that in the next generation 25-30 per cent of all young people everywhere will be degree holders. This foreshadows a very different social and economic world. Studies show that graduates have greater individual agency, independent of income. They are better users of information and communications technologies, have better health outcomes, are more often politically aware and active (McMahon, 2009; OECD, 2015, pp. 46-47), are more likely to move across national borders (OECD, 2016, p. 32), and may be more productive at work.

\section{[Insert Table 1 about here]}

The ubiquitous growth of participation shows when world regions are examined (Table 1). In every region except Central Asia participation has advanced substantially. There has been sharp growth in the Gross Tertiary Enrolment Ratio (GTER) in East Asia since 2010 alone. Aggregated participation in East Asia and the Pacific is largely driven by trends in China. The GTER in China was very low in the 1980s at only 2-3 per cent. Growth accelerated from the late 1990s, with both the state-sanctioned supply of places, and middle class demand for higher education, increasing very rapidly. China's GTER was just under 40 per cent in 2014. In all other systems in East Asia, aside from Vietnam, the GTER now exceeds 50 per cent (UNESCO, 2017).

\section{The WCU Movement}

In higher education, the global systems of research and university comparison, and processes of cross-border isomorphism, feed on each other. One of the strongest patterns of worldwide imitation is the World-Class University (WCU) movement. The WCU movement is also fostered by global systems, those in research and science publishing, and university ranking. Such is the potency of those global systems that it is difficult for countries and research universities to stand aside from the WCU logic. Some nations that cannot muster the necessary resources nevertheless have targets for WCU development (Hazelkorn, 2015).

It is true that there are nations, for example Canada and part of Western Europe, that eschew the terminology of WCUs and hold all universities as formally equal in status regardless of the level of research intensity. In the Netherlands, there are several networked research universities of equivalent quality, without one being clearly dominant. Other nations such as the United Kingdom and Australia reproduce a dominant layer of research institutions while maintaining formal parity of esteem in all designated 'universities'. Nevertheless, in all 
these cases the state fosters research-intensive universities as such. All research-intensive universities are considered 'WCUs' for the purpose of the present article, in which WCU status is understood in terms of material research intensity not normative characteristics.

The advent of the Internet ensured that the global system of English-language science, accessed instantaneously, would dominate all national research systems. In every country, except the US because of its size and research strength, innovations in basic science and industry technologies are largely sourced from world science, not national findings. There is also much growth in cross-border collaboration. Yet the dominance of global research makes national scientific capacity more not less important. To access world science, especially early in a new breakthrough, nations must sustain an indigenous scientific capacity, with research infrastructure and doctoral training in at least some disciplines. They must also work with personnel from abroad, as innovations circulate in research groups before publication, and so must be research makers as well as consumers. Long-term research investment is expensive, but in the last two decades the number of countries producing at least 1000 science papers a year rose from 36 to 51 (NSF, 2014). This growth in and spread of global science underlies the focus on research-intensive WCUs. States want WCUs not simply for national prestige, though that enters policy thinking, but because economies and governments need to have their own strategically vital research capacity. WCUs are therefore nationally-embedded, as well as embedded in the global research system. National funding, regulation and identity provides them with essential conditions of possibility. There are no pure global WCUs; though in a tiny number of cases, such as the George Soros-founded Central European University (2017) in Hungary, they originated from outside the nation of location.

\section{[Insert Table 2 about here]}

In total, 44 countries had at least one top 500 university in the Academic Ranking of World Universities (ARWU) in 2016. While top 500 ranking indicates a substantial material development of research infrastructure, strictly speaking this is a relative rather than absolute measure that cannot capture growth in the absolute number of WCUs and their scientific outputs. Table 2 demonstrates an increase in the number of WCUs at each level of research output. For example, 25 WCUs published more than 10,000 journal papers in 2006-2009. Five years later the number was 46. Some nations have seen spectacular growth. Between 2004 and 2015, using a broad definition of scientific papers that includes editorials and notes, annual papers by authors from China rose from 66,151 to 256,834 (UNESCO, 2015, p. 779).

In 37 of the 44 countries with top 500 research universities, participation as measured by the GTER exceeds 50 per cent. High- and middle-income nations are growing WCUs and mass HEIs at the same time. However, the quality of mass higher education varies markedly. This is another factor that differentiates systems, alongside the number and strength of WCUs, though it receives much less attention than WCUs (Marginson, 2016d).

\section{Organisational Expansion}

National systems vary markedly in institutional size and inter-institutional design, including the extent of vertical stratification, horizontal diversity (differences between HEIs in mission, specialisation or inner culture), or both. The competitive unitary systems in UK and Australia maintain modest horizontal diversity and a steep informal hierarchy of institutions with similar missions, differentiated by research intensity and student selectivity. On the other hand, Nordic and German-speaking countries, and Taiwan and South Korea, maintain horizontal diversity in binary systems, for example between academic and technicalvocational universities, with both types of HEI enjoying standing, though there have been 
recent instances of merger across binary lines. In all binary systems, the leading research universities carry the most social prestige but such systems are less steeply stratified than the US, UK and China (Marginson, 2016d). Another group of countries, including the US, China, Japan and Brazil, sustain complex systems with multiple different individual HEI missions. China and the US use institutional classifications to order an explicit hierarchy while also managing a mission differentiation with horizontal as well as vertical implications.

Research provision is often a major factor in structure. The weightiest distinction between different HEIs derive from comparisons of research extensivity and intensity. Research standing is so important in higher education and so readily measured - for example in competitive funding rounds, and rankings - that the research/non-research distinction mostly has vertical positional implications (Teichler, 2008, pp. 351-352). However, while some nations largely house research in universities, others, including France, Germany and Russia maintain a major role for separate academies, institutes and public laboratories.

There are other kinds of specialist institution, though the role of specialisation varies by country. For example, Russia inherited from the Soviet era many institutions servicing specific industries, for example in engineering, transport, petroleum and nuclear technologies. Countries often have specialist colleges for visual arts, performing arts and/or music. Some run specialist medical universities, postgraduate business schools or teacher training colleges.

In the last generation, in the context of massification, globalisation and organisational modernisation, this worldwide landscape has changed, in the configuration of both national systems and individual HEIs. Matching the expansion of participation, many institutions have grown in size, scope and reach: hence the term 'organisational expansion'. The multiversity form is now more dominant. Overall, HEIs have become externally more homogenous and internally more heterogeneous. In addition, in some systems but not all, marketisation and the WCU movement are associated with greater vertical stratification between HEIs in resources and status. Amid these processes the world's diverse systems and HEIs have become somewhat more similar, though with significant continuing differences. ${ }^{1}$ There appears to be an overall decline in diversity in the horizontal sense (Pinheiro, Charles \& Jones, 2015; Cantwell, Marginson \& Smolentseva, forthcoming), except for on-line and for-profit private forms. Online and for-profit forms are largely peripheral to the established high participation systems. They play a greater role in some emerging nations, such as India and Brazil.

The rise of the large comprehensive research university, Kerr's multiversity, to a more dominant role within systems is consistent with the WCU movement. Multiversities have more resources with which to respond to global challenges, including global rankings. Growth in average institutional size and range is often favoured by states. Governments supervising a smaller number of larger entities secure economies in regulation and more readily devolve social and economic functions to HEIs the size of small cities. Multiversities essay various combinatory forms to secure size and reach, including mergers, multi-site and cross-border institutions (e.g. Johnstone, 2010; Pinheiro, 2015). In many countries the role of large multipurpose institutions has grown not only in the research university sector but in the tiers below. The evolution of more agile, ambiguous and internally diverse structures is often facilitated by a shift from state administration to site governance, within continued state steering and accountability. More ambitious and varied network structures are supported by evolving techniques of multi-site and multi-level management, and devolved budgeting. Organisational modernisation is an essential condition for organisational expansion.

\section{Dynamics of the Multiversity}


In 1963 Clark Kerr described the features of the multi-discipline multiversity as aggregation of ever more diverse functions and activities, ever-accumulation of social and economic status and resources, external extension and internal heterogeneity. It was powered by differing and often conflicting normative principles, including inquiry and knowledge creation, transmission of ideas and values, pastoral care, community service, collegial fellowship, managerial efficiency, and revenue generation. It was replete with competing internal interests and external stakeholders. It became ever more 'multi' via more disciplines, fields of training, research agendas and funding, activities, constituencies and personnel. It engaged with business, the professions, the arts, government, cities and local communities.

Since Kerr this quasi-corporate form of executive led, strategy driven, HEI has spread (Clark, 1998; Marginson \& Considine, 2000; Marginson, 2016c) and its global visibility and connectivity have advanced. Mohrman, Ma and Baker (2008) describe it as the 'global research university' (GRU). Again with the exception of U-Multirank, most ranking systems favour large multi-disciplinary research-active conglomerates and penalise specialist HEIs, sustaining the consensus about the meaning of WCUs (Salmi, 2009). States like multiversities. Societies give them status. A growing proportion of HEIs want to be one. Existing multiversities expand.

It is very significant that institutional higher education has developed and continues to develop by growth and combination, not by the de-bundled missions, nimble specialisation and on-line substitutions persistently suggested by the market imaginary (Marginson, 2016d).

Why does the multiversity accumulate more size, parts and functions? Universities always want to grow their social status and prestige. For leading WCUs, the real end is not revenues, these are merely the means to the end, but the social weight of the university - the figure it cuts in the nation and the larger higher education world (van Vught, 2008), especially through research. Size and multi-disciplinary structure build research. Yet while WCUs accumulate and aggregate, they also need to be student selective and to concentrate their research to maximise quality, setting ultimate limits on expansion. Strikingly, both expansion strategies (quantity) and concentration strategies (quality) generate institutional status. What has changed is that the average point of equilibrium between these two strategies, based on quantity and quality respectively, now seems to be fixed at a larger scale and complexity.

Many elite universities use strategies of managed growth in students, research activity, sites and/or buildings, leveraging their size. China's top WCUs include very large universities such as Zhejiang and Shanghai Jiao Tong, and medium sized research specialists such as Jilin and the University of Science and Technology. Like Harvard, Tsinghua works vigorously with all of size, a broad-based research culture, and concentrated excellence. Size is a principal tool of Toronto and University College London. Some other WCUs stay small. In 2016, Caltech had 1001 first degree students and 1251 at graduate level. With 2255 students its research budget was the same as that of the University of Toronto with 86,709 students (California Institute of Technology, 2016: University of Toronto, 2016). Yet Caltech is unusual, the extreme case of the selective WCU. In most other WCUs the two drivers, selectivity and aggregation, are combined in varying ways. Many follow selective or aggregative logics variously in different parts of their operation. The flexible multiversity form permits that. High value brands (and marketing) cover for the less selective areas. Variations in the use of selective and expansionary strategies, and in the contents of what is selective and aggregated, are one key to the individual distinctiveness of WCUs.

\section{WCUs in China}


The number of recognised WCUs in mainland China has grown remarkably, from eight of the world top 500 in the Shanghai ARWU in 2005 to 41 in 2016. Tsinghua was 58th in 2016 and Peking $71^{\text {st }}$, with Fudan, Shanghai Jiao Tong, Zhejiang and the University of Science and Technology in the world top 150. China's WCUs would be more highly placed in the ARWU if it was not for ARWU's use of Nobel Prizes as an indicator. This factor also understates the rise of Singapore's NUS and Nanyang University of Technology (ARWU, 2017).

The publication and citation quality data used by the Leiden ranking are free of the Nobel factor. In total number of science papers published in 2011-2014, China had seven of the world's top 50 universities, led by Zhejiang in fourth place and Tsinghua in seventh place, pointing to China's use of large scale in much of its WCU development. Leiden also measures the number of research papers in the top 10 per cent of their field by citation rate, the quantity of quality - the volume of high quality research produced. Here China's performance was weaker than in total papers. In 2011-2014, China had four of the top 50 WCUs, led by Tsinghua (31), Zhejiang (33), Shanghai Jiao Tong (48) and Peking (50), and nine in the world top 100. In the top 100 China was second nation but well behind the US with 48 of the top 100 WCUs. Of the top 800 universities in the world, in terms of high citation papers, 112 were from China and 173 from the US (Leiden University, 2017).

China's number of top 10 per cent papers by citation had markedly improved over the previous five years. In 2006-2009, China had three WCUs in the top world 100 on this measure, led by Tsinghua in $63^{\text {rd }}$ place, compared to nine WCUs in 2011-2014. The number of top 10 per cent papers published by Tsinghua researchers increased from 830 in 20062009 to 1453 in 2011-2014, growth of 75.1 per cent in five years (Leiden University, 2017).

\section{[Insert Table 3 about here]}

The performance of China's WCUs in high citation English-language science varies markedly by discipline. Physical Sciences, Engineering, Mathematics and Complex Computing are now strong, Life Sciences and Medicine comparatively weaker and Social Sciences and Psychology very weak. In Mathematics and Computing, Tsinghua was first in the world in 2011-2014 on the basis of top 10 per cent papers, followed by MIT, Nanyang in Singapore and Stanford. In these fields China had seven of the first 15 WCUs, including City University of Hong Kong. a result probably largely due to China's research on Complex Computing. The US had five of the top 15. In Physical Sciences and Engineering, China had four WCUs in the top 15 and the US had five. Tsinghua was fourth in the world. Both Singapore WCUs were in the top ten in each discipline group (Leiden University, 2017).

\section{A Distinctive Model of the University?}

These data of research performance undermine assumptions that only American or Western governance and academic cultures are compatible with stellar intellectual creativity in peergroup mediated science. China has achieved equivalent global science in Mathematics, Physical Sciences and their applications to North America and Western Europe, using a different mode of higher education. China shares the process of corporate modernisation, and as in English-speaking systems, uses HEI competition and performance regimes to lift measured outputs (perhaps with the same potential costs in disciplinary cultures). However, it blends these globally familiar measures with state-university relations where both university leaders, academic president and party secretary, are appointed by official ministries; WCUs are part of the state and servants of the public good; and academic freedom is understood more in terms of Berlin's (1969) positive freedom than negative freedom. China's practices of academic freedom, predating today's party-state, emphasise the connectedness, 
responsibility and authority of professors, rather than primarily focusing on the absence of external constraints as in the US (Zha, 2011). The flourishing of the Physical Sciences cluster in China is as much because of, not despite, state commitment and supervision.

Is this sufficient to constitute a distinctive Chinese model of WCU in the Post-Confucian Chinese civilizational region, where East Asia and Singapore share something of the same state supervision approach, with its common roots in Qin/Han dynasty China? Probably not. Governance, which is more means than end, in not sufficient for a distinctive model of higher education. The heart of a university is the knowledge in which scholars and students are immersed. Despite the depth of Confucian educational cultivation in society, China's WCUs have yet to develop a distinctive teaching/learning mission. Nor have they fully joined the national traditions in medicine and humanities to global disciplinary conversations. Perhaps to achieve that it is necessary for Putonghua to become a global language. There are also other questions about the approach to disciplines other than the Physical Sciences cluster, especially non-scientific fields. It is partly a matter of relative funding, and partly a question of whether state policy, institutional governance and academic organisation nurture acrossthe-board creativity. State and executive supervision of WCUs are compatible with creativity if academic judgments are consistently devolved, including funding allocation in research; and there is money, time and space for productive work and the communication of expertise.

Clark Kerr (1963/2001) assumed that in research multiversities all disciplines should flourish, while noting that US research funding had consigned the non-science disciplines to an increasingly subordinate position, resulting in an imbalance that should be addressed ( $\mathrm{p}$. 90). Disciplinary imbalances continue in the US and UK and are more apparent in postConfucian systems. Yang (2014) argues that the humanities, which shape cultural identity, might be an essential building block of a Chinese 'Idea of a University' (Newman, 1852/1996). It remains to be seen whether China will develop its own comprehensive WCU that includes free and fecund social sciences and humanities. If it does so, that WCU will be a more formidable instrument of both national reflexivity and global relations of soft power.

\section{Acknowledgements}

This is the revised version of a paper presented at the PKU-Stanford Joint Forum on 'Building World-Class Universities: An Institutional Perspective', Peking University, Beijing, 4-5 November 2016. Thank you to Ha Wei, Min Weifang and especially Ruth Hayhoe.

\section{Note}

\footnotetext{
${ }^{1}$ This section of the article draws on a cross-country project on higher participation higher education systems, that includes United States, Canada, Australia, Ireland, Norway, Finland, Poland, Russia and Japan.
} 


\section{References}

Academic Ranking of World Universities, ARWU (2017). Shanghai Jiao Tong University Graduate School of Education. <http://www.shanghairanking.com/index.html>

Bayly, C. (2004). The Birth of the Modern World 1780-1914: Global connections and comparisons. Oxford: Blackwell.

Berlin, I. (1969). Two concepts of liberty. In I. Berlin, Four Essays on Liberty. Oxford: Oxford University Press.

California Institute of Technology (2016). Caltech at a Glance.

<https://www.caltech.edu/content/caltech-glance>

Cantwell, B., Marginson, S. \& Smolentseva, A. (Eds.) (forthcoming). High Participation Systems of Higher Education [under review]

Carnoy, M. (1984/2014). The State and Political Theory. Princeton: Princeton University Press.

Carnoy, M., Froumin, I., Leshukov, O. \& Marginson, S. (Eds.) (forthcoming). Federalism in Higher Education: A comparative study. [under review]

Carnoy, M., Loyalka, P., Dobryakova, M., Dossani, R., Froumin, I., Kuhns, K., Tilak, J.B. \& Rong W. (2013). University Expansion in a Changing Global Economy: Triumph of the BRICs? Stanford: Stanford University Press.

Central European University (2017). Website. https://www.ceu.edu

Cerny, P. (1997). Paradoxes of the competition state: The dynamics of political globalization. Government and Opposition, 32 (2), 251-274

Cheng, K.-M. \& Yang, R. (2016). A cultural value in crisis: Education as a public good in China. In O. Filippakou \& G. Williams (Eds.), Higher Education as a Public Good: Critical perspectives on theory, policy and practice (pp. 127-139). New York: Peter Lang.

Chirikov, I., Watanabe, S. \& Postiglione, G. (forthcoming). Rethinking the role of the state in global competition in higher education: The implementation of global excellence initiatives in China, Japan and Russia. Paper sent to Higher Education.

Clark, B. (1998). Creating Entrepreneurial Universities: Organizational pathways of transformation. Oxford: Pergamon.

Cuncliffe, B. (2015). By Steppe, Desert and Ocean: The birth of Eurasia. Oxford: Oxford University Press.

Dearden, L. (2017). Creating competition in higher education: Economic myths and realities. Keynote address to the conference of the ESRC/HEFCE Centre for Global Higher Education, London, 1 March. <http://www.researchcghe.org/perch/resources/lorraine-dearden-1.pdf> 
Dewey, J. (1927). The Public and Its Problems. New York: H. Holt. Reprinted by Ohio University Press.

Drori, G., Meyer, J. \& Hwang, H. (eds.) (2006). Globalization and Organization: World society and organizational change. Oxford: Oxford University Press.

Evans, P., Rueschemeyer, D. \& Skocpol, T. (Eds.) (1985). Bringing the State Back In. Cambridge: Cambridge University Press.

Frankopan, P. (2015). The Silk Roads: A new history of the world. London: Bloomsbury.

Fukuyama, F. (1989). The end of history? The National Interest, 16, 3-18.

Goedegbuure, L. (1993). Mergers in Higher Education: A comparative perspective. London: Kogan Page.

Goedegbuure, L., Kaiser, F., Maassen, P., Meek, L., van Vught, F. and de Weert, E. (eds.) (2014). Higher Education Policy: An international comparative perspective. Oxford: Pergamon.

Guzman-Valenzuela, C. (2016). Global trends and their impact on Latin America: The role of the state and the private sector in the provision of higher education. Working Paper 4, ESRC/HEFCE Centre for Global Higher Education, London.

<http://www.researchcghe.org/perch/resources/publications/wp4.pdf>

Hayhoe, R., Li, J., Lin, J. \& Zha, Q. (Eds) (2011). Portraits of 21st Century Chinese Universities. Hong Kong: Springer/CERC, U Hong Kong.

Hazelkorn, E. (2015). Rankings and the Reshaping of Higher Education: The battle for world-class excellence. 2nd edn. Houndmills: Palgrave Macmillan.

Johnstone, B. (2010). Higher educational diversification in the United States. In Research Institute for Higher Education (RIHE), Hiroshima University, Diversifying Higher Education Systems in the International and Comparative Perspectives (pp. 1-21). Hiroshima: RIHE.

Kerr, C. (1963/2001). The Uses of the University. 5th edition. Cambridge, MA: Harvard University Press. First published 1963.

King, R., Marginson, S. \& Naidoo, R. (Eds.) (2011). Handbook of Globalization and Higher Education. Cheltenham: Edward Elgar.

Kwiek, M. (2016). De-privatisation in higher education: A conceptual approach. Higher Education, DOI: 10.1007/s10734-016-0047-3

Leiden University (2016). CWTS Leiden Ranking 2016. Centre for Science and Technology Studies, CWTS. <www.leidenranking.com>

McMahon, W. (2009). Higher Learning Greater Good. Baltimore, MD: The Johns Hopkins University Press. 
Marginson, S. (2006). Dynamics of national and global competition in higher education. Higher Education, 52 (1), 1-39.

Marginson, S. (2010). Space, mobility and synchrony in the knowledge economy. In S. Marginson, P. Murphy \& M. Peters, Global Creation: Space, Mobility and Synchrony in the Age of the Knowledge Economy (pp. 117-49). New York: Peter Lang.

Marginson, S. (2013). Emerging higher education in the post-Confucian heritage zone. In D. Araya \& P. Marber (Eds.), Higher Education in the Global Age (pp. 89-112). Routledge, New York.

Marginson, S. (2014). University rankings and social science. European Journal of Education, 49 (1), 45-59.

Marginson, S. (2016a). High-participation systems of higher education. Journal of Higher Education, 87 (2), 243-70.

Marginson, S. (2016b). The worldwide trend to high participation higher education: Dynamics of social stratification in inclusive systems. Higher Education, 72 (4), 413-435. Open access publication at: 〈http://rdcu.be/kf7P>

Marginson, S. (2016c). The Dream is Over: The crisis of Clark Kerr's California idea of Higher Education. Berkeley: University of California Press.

Marginson, S. (2016d). Higher Education and the Common Good. Melbourne: Melbourne University Press.

Marginson, S. (2017). Global trends in higher education financing: The United Kingdom. International Journal for Educational Development. Published online at http://dx.doi.org/10.1016/j.ijedudev.2017.03.008

Marginson, S. \& Considine, M. (2000). The Enterprise University: Power, governance and reinvention in Australia. Cambridge: Cambridge University Press

Marginson, S., \& Rhoades, G. (2002). Beyond national states, markets, and systems of higher education: A glonacal agency heuristic. Higher Education, 43 (3), 281-309.

Mettler, S. (2014). Degrees of Inequality: How the politics of higher education sabotaged the American Dream. New York: Basic Books.

Mohrman, K., Ma, W. and Baker, D. (2008). The research university in transition: The emerging global mode. Higher Education Policy, 21 (1), 5-27.

Musselin, C. (2005). European academic labour markets in transition. Higher Education, 49 (1), 135-154

Naidoo, R. (2004). Fields and institutional strategy: Bourdieu on the relationship between higher education, inequality and society. British Journal of Sociology of Education, 25 (4), 457-471. 
National Science Foundation, NSF (2014). Science and Engineering Indicators 2014. <http://www.nsf.gov/statistics/seind14/>

Newman, J. (1996). The Idea of a University. Newhaven: Yale University Press. First published in 1852 and 1858.

Ordorika, I. (2003). Power and Politics in University Governance: Organization and change at the Universidad Nacional Autonoma de Mexico. New York: Routledge.

Organization for Economic Cooperation and Development, OECD (2015). Education at a Glance. Paris: OECD.

Organisation for Economic Cooperation and Development (OECD) (2016). Perspectives on Global Development 2017: International migration in a shifting world. $<$ http://www.keepeek.com/Digital-Asset-Management/oecd/development/perspectives-onglobal-development-2017_persp_glob_dev-2017-en\#page1>

Pinheiro, R. (2015). HPS and Diversity: The case of Norway. Paper prepared for High Participation Systems comparative project. See B. Cantwell, S. Marginson \& A. Smolentseva (Eds.). (forthcoming). High Participation Systems of Higher Education [under review]

Pinheiro, R., Charles, D. \& Jones, G. (2015). Equity, institutional diversity and regional development: A cross-country comparison. Higher Education, 72 (3), 307-322.

Quacquarelli Symonds (QS) (2016). QS world university rankings. <www.topuniversities.com/university-rankings>

Robertson, S., Olds, K., Dale, R. \& Dang, Q. A. (Eds.) (2016). Global Regionalisms and Higher Education: Projects, processes, politics. Cheltenham: Edward Elgar.

Salmi, J. (2009). The Challenge of Establishing World-Class Universities. World Bank Publications. Washington: World Bank.

Schofer, E., \& Meyer, J. (2005). The worldwide expansion of higher education in the twentieth century. American Sociological Review, 70 (6), 898-920.

Shahjahan, R. \& Kezar, A. (2013). Beyond the 'National Container': Addressing methodological nationalism in higher education research. Educational Researcher, 42 (1), 20-29.

Slaughter, S., \& Rhoades, G. (2004). Academic Capitalism and the New Economy: Markets, state, and higher education, Baltimore, N.J.: Johns Hopkins University Press.

Smolentseva, A. (2017). Universal higher education and positional advantage: Soviet legacies and neoliberal transformations in Russia. Higher Education, 73 (2), 209-226.

Teichler, U. (2008). Diversification? Trends and explanations of the shape and size of higher education. Higher Education, 56 (3), 349-379 
Times Higher Education (2016). World university rankings.

<www.timeshighereducation.com/world-university-rankings>

Trow, M. (1973). Problems in the Transition from Elite to Mass Higher Education. Berkeley, CA: Carnegie Commission on Higher Education.

U-Multirank (2017). Website.

http://www.umultirank.org/\#!/home?name=null\&trackType=home

United Nations Educational, Social and Cultural Organisation (2015). UNESCO Science

Report 2015. Paris: UNESCO

United Nations Educational, Social and Cultural Organisation, UNESCO (2017). UNESCO Institute for Statistics data on education. <http://data.uis.unesco.org>

University of Toronto (2016). Quick Facts. 〈https://www.utoronto.ca/about-u-of-t〉

Välimaa, J. (2011). The corporatization of national universities in Finland. In B. Pusser, K. Kempner, S. Marginson and I. Ordorika (Eds.), Universities and the Public Sphere (pp. 10119). New York: Routledge

Välimaa, J. \& Nokkala, T. (2014). The dimensions of social dynamics in comparative studies on higher education. Higher Education, 67 (4), 423-437.

van Vught, F. (2008). Mission diversity and reputation in higher education. Higher Education Policy, 21 (2), 151-174.

Wimmer, A. \& Schiller, M. (2002). Methodological nationalism and beyond: Nation-state building, migration and the social sciences. Global Networks, 4 (2), 301-334.

Yang, R. (2014). China's strategy for the internationalisation of education: An overview. Frontiers of Education in China, 9 (2), 151-162.

Zha, Q. (2011). Is there an emerging Chinese model of the university? In R. Hayhoe, J. Li, J. Lin \& Q. Zha (Eds), Portraits of 21st Century Chinese Universities (pp. 451-71). Hong Kong: Springer/CERC, U Hong Kong. 
Table 1. Regional Gross Tertiary Enrolment Ratios (\%), 1970-2010 and 2014

\begin{tabular}{|c|c|c|c|c|}
\hline & 1970 & 1990 & 2010 & 2014 \\
\hline World & 10.0 & 13.6 & 29.3 & 34.5 \\
\hline North America and Western Europe & 30.6 & 48.6 & 76.9 & 76.4 \\
\hline Central and Eastern Europe & 30.2 & 33.9 & 67.9 & 74.4 \\
\hline Latin America and the Caribbean & 6.9 & 16.9 & 40.9 & 44.7 \\
\hline East Asia and Pacific & 2.9 & 7.3 & 27.3 & 39.1 \\
\hline Arab States & 6.0 & 11.4 & 25.5 & 28.9 \\
\hline Central Asia & n.a. & 25.3 & 26.7 & 25.7 \\
\hline South and West Asia & 4.2 & 5.7 & 17.4 & 22.8 \\
\hline Sub-Saharan Africa & 0.9 & 3.0 & 7.7 & 8.2 \\
\hline
\end{tabular}

n.a. = data not available

Source: UNESCO, 2017 
Table 2. Number of world universities at different levels of science paper production over four years (10,000, 5000, 2000 and 1200 papers), change between 2006-2009 and 2011-2014, inclusive

\begin{tabular}{|l|c|c|c|c|c|c|}
\hline $\begin{array}{l}\text { Universities publishing } \\
\text { more than }\end{array}$ & 2006-2009 & 2007-2010 & 2008-2011 & 2009-2012 & 2010-2013 & 2011-2014 \\
\hline 10,000 papers & 25 & 26 & 31 & 34 & 39 & 46 \\
\hline 5000 papers & 122 & 128 & 135 & 143 & 154 & 171 \\
\hline 2000 papers & 381 & 402 & 425 & 452 & 481 & 496 \\
\hline 1200 papers & 594 & 629 & 657 & 682 & 712 & 743 \\
\hline
\end{tabular}

Source: Leiden University, 2017 
Table 3. World leading WCUs in (1) Physical Sciences and Engineering and (2) Mathematics and Complex Computing, as measured by the total number of published papers, in 2011-2014 inclusive, that were in the top 10 per cent of their research field by citation rate

\begin{tabular}{|c|c|c|c|c|c|}
\hline $\begin{array}{l}\text { world } \\
\text { rank }\end{array}$ & University and system & $\begin{array}{l}\text { Physical } \\
\text { Sciences \& } \\
\text { Engineering }\end{array}$ & $\begin{array}{l}\text { world } \\
\text { rank }\end{array}$ & University and system & $\begin{array}{l}\text { Mathematics } \\
\text { \& Complex } \\
\text { Computing }\end{array}$ \\
\hline 1 & UC Berkeley USA & 1215 & 1 & Tsinghua U CHINA & 280 \\
\hline 2 & Massachusetts IT USA & 1154 & 2 & Massachusetts IT USA & 246 \\
\hline 3 & Stanford U USA & 936 & 3 & Nanyang TU SINGAPORE & 243 \\
\hline 4 & Tsinghua U CHINA & 894 & 4 & Stanford U USA & 215 \\
\hline 5 & Harvard U USA & 834 & 5 & Zhejiang U CHINA & 205 \\
\hline 6 & Nanyang TU SINGAPORE & 797 & 6 & UC Berkeley USA & 201 \\
\hline 7 & U Cambridge UK & 764 & 7 & Huazhong UST CHINA & 198 \\
\hline 8 & Zhejiang U CHINA & 732 & 8 & U Texas, Austin USA & 193 \\
\hline 9 & NU Singapore SINGAPORE & 670 & 9 & NU Singapore SINGAPORE & 187 \\
\hline 10 & U Tokyo JAPAN & 664 & 10 & City U Hong Kong HK SAR & 180 \\
\hline 11 & U Science \& Tech. CHINA & 633 & 11 & Harbin IT CHINA & 180 \\
\hline 12 & U Michigan USA & 627 & 12 & U Michigan USA & 169 \\
\hline 13 & ETH Zurich SWITZERLAND & 626 & 13 & Xidian U CHINA & 168 \\
\hline 14 & Caltech USA & 613 & 14 & Shanghai JT U CHINA & 164 \\
\hline 15 & Peking U CHINA & 579 & 15 & ETH Zurich SWITZERLAND & 164 \\
\hline
\end{tabular}

Source: Leiden University, 2017 